\title{
Fibroblast-dependent regulation of the stem cell properties of cancer cells
}

\author{
Minireview $^{* *}$
}

A. WEILAND ${ }^{1}$, P. ROSWALL ${ }^{2}$, T. C. HATZIHRISTIDIS ${ }^{3}$, K. PIETRAS $^{2}$, A. OSTMAN ${ }^{3}$, C. STRELL ${ }^{3, *}$

${ }^{1}$ Department of Urology, Laboratory of Molecular Biology, Jena University Hospital, 00740 Jena, Germany; ${ }^{2}$ Department of Medical Biochemistry and Biophysics, Karolinska Institutet, 17177 Stockholm Sweden; ${ }^{3}$ Department of Oncology-Pathology, Cancer Center Karolinska, Karolinska Institutet, 17176 Stockholm, Sweden

${ }^{*}$ Correspondence: carina.strell@ki.se

Received May 13, 2012 / Accepted July 5, 2012

\begin{abstract}
There is emerging evidence that cancer stem cells (CSCs), like normal tissue stem cells, are regulated by a niche formed of mesenchymal cells. In this review we summarize the current knowledge of the role of cancer associated fibroblasts (CAFs) in a tentative CSC niche. We also discuss findings from our own studies showing that CAF derived factors have a strong stimulatory effect on the stem cell properties of breast cancer cells. Based on recent literature we conclude that CAFs are strong modulators of the stem cell properties of cancer cells. This effect is likely to be particularly relevant under circumstances of early stages of tumor cell dissemination and metastasis.
\end{abstract}

Key words: cancer associated fibroblasts, cancer stem cells, niche, tumor formation, metastasis

Nowadays it is increasingly accepted that tumor cells are a heterogeneous population composed of subpopulations of cells that share certain properties with normal stem cells, such as the ability to self-renew and the expression of stem cell markers [1]. These so called cancer stem cells (CSCs) are highly tumorigenic when injected into mice [2] and subsequent studies have shown that these cells are particularly responsible for tumor metastasis [3] and resistance towards radiation or chemotherapy [4,5]. CSCs have been described and isolated from various tumor tissues including breast [2], prostate [6], colon [7], brain [8] and pancreas [9].

In recent years it has also become evident that tumor growth and progression are not just determined by properties of the malignant cancer cells themselves, but also by the tumor microenvironment. The tumor microenvironment includes endothelial cells, pericytes and cancer associated fibroblasts (CAFs) as well as immune cells, bone marrow derived cells and the extracellular matrix [10]. All these cells interact - directly and indirectly- with the tumor cells, thereby affecting tumor progression and disease outcome. Since normal stem cells are regulated in defined niches involving different mesenchymal cells $[11,12]$ the question has been raised whether CSCs are also regulated in certain niches located within the complex tumor microenvironment.

This review will focus only on the role of fibroblasts in regulating CSCs. Some recent findings from our own studies will also be included. In brief, we will first describe the functions of fibroblasts in normal stem cell niches. The two main parts will describe evidences for a role of fibroblasts in CSC niches and their impact on CSC phenotypes. The final part will give an overview on roles of fibroblasts in the formation of the premetastatic niche. For more detailed reviews on the current status of tumor microenvironmentdependent regulation of CSCs we refer to other recent reviews [13-16].

Fibroblasts in stem cell niches. The term stem cell niche was first introduced by Schofield in 1978, who defined a stem cell niche as an anatomical compartment in which the local

${ }^{* *}$ Presented on the XX. Biological Days - Stem cells - from regenerative medicine to cancer, Pilsen, October 25-27, 2011 
microenvironment regulates stem cell maturation and self renewal $[11,17,18]$.

These niches are formed by neighboring cells, including epithelial and stromal cells, as well as the extracellular matrix $[12,19]$. The signals provided by the niche can be secreted molecules and matrix components as well as cell surface proteins.

There are a number of excellent reviews describing stem cells niches of the bulge of hair follicle [12,20,21], the bone marrow $[22,23]$ and the crypts of the colon and small-intestinal villi [15]. With regard to other organs, including breast, stem cell niches are much less described if identified at all.

In the crypts of the intestine stromal cells release bone morphogenic proteins (BMPs), which block proliferative Wnt and Notch signals, thereby fostering differentiation. At the crypt bottom BMPs are inhibited by noggin, which acts as a scavenger receptor to inhibit the binding of BMPs to their signaling receptors $[15,24,25]$. Similar processes regulate the start of hair growth cycles, where the niche receives stimuli from specialized mesenchymal cells - the so called dermal papilla - that stimulate stem cells within the bulge to differentiate downwards to regrow a new hair follicle [12]. Although there is also strong evidence for a stroma dependency within the mammary stem cell niche, stroma derived signals - positive as well as negative - still need to be identified [19]. In contrast to the mouse mammary gland, where the epithelium is mainly embedded in adipose tissue, the human mammary epithelium is embedded in extracellular matrix with interlobular fibroblasts and many blood vessels [26]. In vivo transplantation experiments showed that epithelial outgrowth within the cleared mammary fat pad of mice did only occur in the presence of fibroblasts and/or collagen gels indicating indeed a strong dependency on the microenvironment [19,27-29].

Further evidence for the importance of the microenvironment was provided by experiments including injection of alveolar bud stem cells isolated from pregnant mice into the cleared fat pad of pubertal mice $[19,30]$. These cells switched to a pubertal developmental program indicating that their phenotype was largely controlled by the microenvironment.

Evidences for the role of fibroblasts in cancer stem cell niches. Because of their role in normal stem cell niches the question was raised if fibroblasts play also a role in the regulation of CSCs.

Many solid tumors are characterized by a strong infiltration of activated fibroblasts, so called cancer associated fibroblasts (CAFs), which phenotypically resemble myofibroblasts found during woundhealing. CAFs are mainly defined by the expression of certain markers like $\alpha$-smooth-muscle actin ( $\alpha \mathrm{SMA}$ ), fibroblast-activated protein (FAP), fibroblast-specific protein1 (FSP1/S100A4), neuron-glial antigen-2 (NG2) and PDGF $\beta$-receptor. Not all markers are expressed by all CAFs, and different marker combinations probably reflect different CAF subtypes [31] (for CAF reviews please see [31-33]). CAFs are further characterized by the release of growth factors such as TGF-beta or hepatocyte growth factor (HGF) $[31,32,34]$, but also chemokines [35,36] and proteases [37]. In addition, stem cells and CSCs were shown to be regulated by Wnt, Notch, BMPs, hedgehog as well as cytokines and chemokines giving an indication for a possible CAF CSC interaction $[15,38,39]$. Earlier studies have demonstrated that especially tumor cells located in close proximity to the CAF interface show a nuclear expression of beta-catenin [40] as it is also observed in CSCs. Also in breast cancer it was shown that $\mathrm{CD} 44^{+} \mathrm{CD} 90^{+} \mathrm{CSC}$ like cells are located mainly at the tumor periphery adjacent to $\mathrm{CD} 90^{+}$fibroblastic cells at the invasive front indicating a tumor growth from "the outside" [41].

The first study giving strong evidence of a fibroblast-dependent regulation of CSCs was published by Vermeulen et al [34] who showed that primary isolated colon CAFs, as well as a myofibroblast cell line, release HGF which induced a nuclear translocation of beta-catenin in tumor cells thereby inducing a stem cell typical gene transcription profile. To identify CSCs a TCF/LEF reporter gene assay was performed to monitor Wnt-dependent expression of EGFP. High reporter gene activity was associated with high expression of colon CSC markers and the up-regulation of the c-Met receptor. The stimulatory effect of $\mathrm{CAF} /$ myofibroblast conditioned medium on the Wnt-reporter activity could be blocked by a neutralizing antibody against HGF or a specific inhibitor against the HGF receptor c-Met. The CAF induced CSCs also had a higher tumorigenicity in a subcutaneous xenograft tumor model. In addition, it was demonstrated that HGF secreted by myofibroblasts induces a CSC phenotype in differentiated tumor cells, indicating a high degree of plasticity between CSCs and more differentiated tumor cells.

These interesting findings were supported by later studies showing that basal-like human mammary epithelial cells can spontaneously dedifferentiate into stem-like cells [42]. A stem cell like state overlaps highly with a mesenchymal state characterized by the up-regulation of transcription factors like Twist, Snail, Slug and ZEB and the expression of N-Cadherin, vimentin and fibronectin [43]. Within these studies it was further demonstrated that cells that acquired stem cell/mesenchymal properties by exposure to an induction cocktail including recombinant TGF-beta and Wnt5a, neutralizing antibodies against DKK1 and E-cadherin in combination with short hairpin RNA-mediated knock-down of SFRP1 develop autocrine signaling loops keeping them in an autonomous stem cell/mesenchymal state independent from external stimuli [43]. This induced phenotype was so far demonstrated only after exogenous addition of this induction cocktail over a defined time frame. If CAF-secreted factors have a similar capacity, remains to be shown.

Another study dealing with pancreatic ductal adenocarcinoma (PDAC) presented the first evidence for therapeutic benefit of targeting the CSC niche formed by activated pancreatic stellate cells (PSCs) [44]. PDAC is a tumor disease characterized by a very strong infiltration of myofibroblasts [45]. PSCs reside in a quiescent state in the exocrine pancreas and become myofibroblast-like and start to proliferate upon 
A

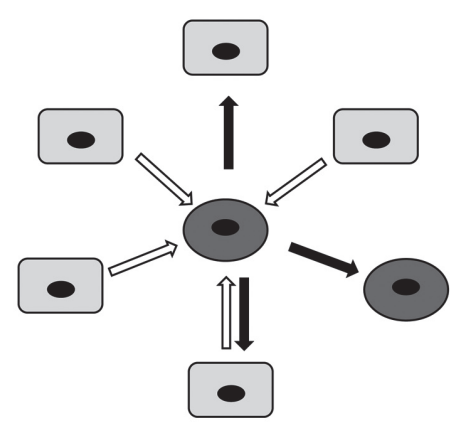

C

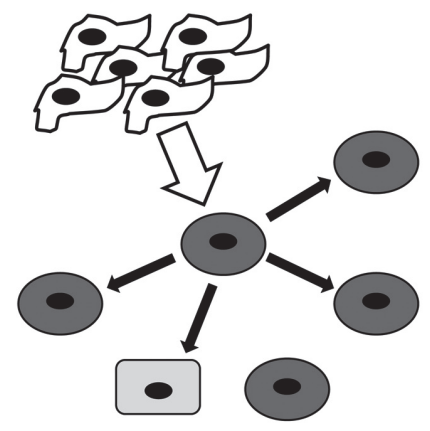

B

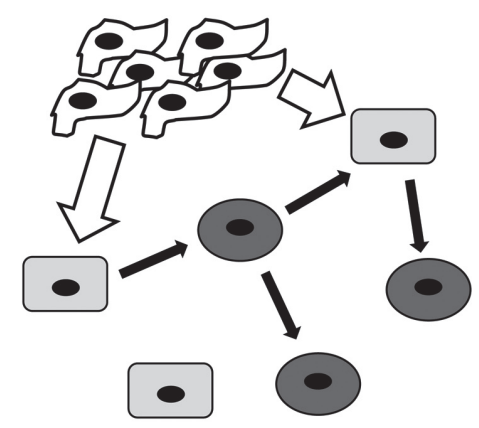

D

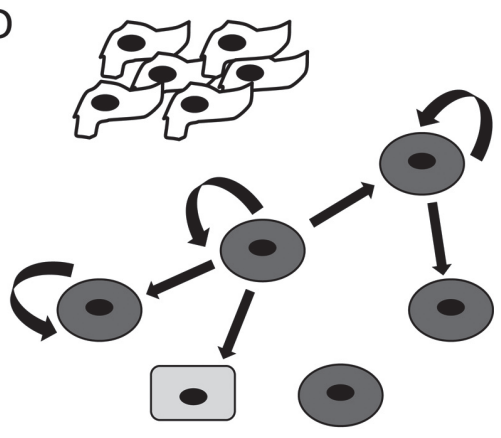

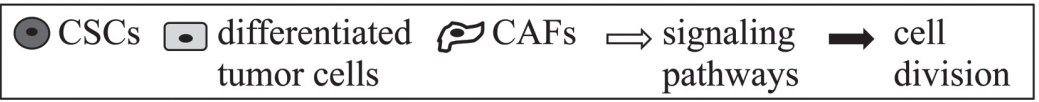

Figure 1. CAF dependent modulation of CSCs

(A) CSCs have the ability to self-renew and to give raise to more differentiated tumor cells (B) CAF can induce a stem cell phenotype in more differentiated tumor cells, thereby increasing the CSC pool (C) CAF can also act directly on CSCs and promote their self-renewal (D) CAF derived signals can induce a CSC phenotype that is independent from external signals because of autocrine signaling loops.

inflammatory processes and tissue injury [46]. The study by Lonardo et al [44] showed that activated PSCs -in contrast to their quiescent counterpart - express Nodal and Activin, two members of the TGFbeta family. Co-culture experiments using different sets of primary isolated pancreatic tumor cells and immortalized PSCs isolated from chronic pancreatitis showed a PSC mediated increase in sphere formation of pancreatic cancer cells which could be abrogated by pretreatment with an inhibitor against Alk4/7, the receptor for Nodal and Activin. Based on these observations the authors suggested that targeting PSCs e.g. by hedgehog inhibitors could be an important step to develop more effective therapies for PDAC. Consequently, they could demonstrate in an ortothopic transplantation model of human pancreatic cancer tissue in nude mice that a triple combination therapy, of a hedgehog and an Alk4/7 inhibitor together with gemcitabine, resulted in effective inhibition of disease progression.

CSC phenotypes regulated by CAFs. There are thus strong indications that CAFs can regulate CSCs in several ways by (a) acting directly on CSC and promoting their self renewal or (b) re-inducing a stem cell phenotype in more differentiated tumor cells (reprogramming) or (c) induction of autocrine signaling loops in tumor cells that keep them in a stem cell like state (Fig. 1).

To dissect which of these mechanisms dominates in various settings, different experimental setups can be used. The potential of CAFs to promote the self-renewal of CSCs can be investigated by exposure of a tumor cell population that is enriched for cells expressing CSC marker (e.g. CD133+) to CAF conditioned medium and by monitoring the sphere forming capacity. Reprogramming of more differentiated tumor cells can be tested by exposure of a more differentiated tumor cell population to CAF conditioned medium and investigation of alterations in the fraction of sphere-forming cells. Stimulatory effects on self-sustaining autocrine signaling can be tested in a second round of sphere formation using non-conditioned control medium.

We have addressed these questions in a model system using cells from tumors of MMTV-PyMT breast cancer model (described in [47]). Therefore, we isolated primary tumor cells 
(I3TC) and CAFs from a tumor of this mouse model. CAFs were isolated via outgrowth assays and immortalized by serial passaging. The cells were determined to be free from fibroblast and epithelial cell contamination respectively.

We performed a limited dilution assay (LDA) with the I3TC tumor cells using non-conditioned medium, CAF conditioned medium and conditioned medium of the tumor cells. The latter was used to define if the observed effects are fibroblast-specific. The number of spheroids was counted after 2 weeks. Compared to the non-conditioned medium both conditioned media were significantly more potent in inducing sphere formation in I3TC cells ( $\mathrm{p}<0,0001$ for both conditions). Furthermore, the CAFderived conditioned medium was significantly more potent than the tumor cell-derived conditioned medium $(\mathrm{p}=0,008)$ (Fig. 2A).

The question of whether the obtained spheroids developed autocrine signaling loops, and became independent of factors provided by the conditioned medium, was addressed through the collection and re-dissociation of the spheroids grown in conditioned medium followed by a second round of LDA in non-conditioned medium. Due to the very low yield of spheroids in the cultures with non-conditioned medium, these analyses were restricted to spheroids formed after exposure to medium conditioned by CAFs or tumor cells. In this second round of LDA, in non-conditioned media, the sphere growth was analyzed after 3 weeks to detect spheroids larger than $50 \mu \mathrm{m}$, which was the pre-defined cut-off.

The sphere forming capacity of the I3TC cells in the second round of LDA was a bit lower than the sphere forming capacity of the control cells in the non-conditioned medium in the first LDA when counted after 3 weeks ( $p<0,05$ for both conditions) (Fig. $2 \mathrm{~B}+\mathrm{C}$ ). This indicates that the cells did not become independent from the conditioned medium and that the frequency of self-renewing cell divisions -and thereby the frequency of CSCs- was not increased.

Stem cells are regulated by the activation of different pathways including Notch signaling, hedgehog, Wnt and BMPs $[15,38,39]$. In addition CSCs have been shown to express several embryonic stem cell markers like e.g. Nanog, Sox2, Oct or Bmi-1 [48-51]. Via real-time PCR analysis we investigated if the I3TC spheroids, formed after growth in the different conditioned medium, varied with regard to their "stemness" gene expression profile or "stemness" pathway activation.

CAF conditioned media and the tumor conditioned medium induced a similar stemness gene expression profile showing only a minor up-regulation of stemness marker when compared to the spheroids grown in non-conditioned medium (Fig. 2D). A slight, but not significant, increase in the expression of genes indicating Notch-, Wnt- and hedgehog-pathway activation was observed. In contrast, expression of the stem cell markers Bmi or Nanog, and the differentiation marker GATA-3, did not show any differences.

These data indicate that the conditioned media mainly affects the number of cells able to form spheroids, without major impact on the cellular spheroid composition.
Taken together, we have shown evidence that CAF-released factors can increase the sphere forming capacity of mouse breast cancer cells but the effect is not fibroblast-specific since tumor cell released factors are equally potent. It is noteworthy, that these analyses of the effects of tumor cell-derived factors should be included in studies analyzing paracrine control of cancer stem cells.

One situation, where paracrine signaling from stromal cells can be of particular importance, includes the early stages of metastasis when single or few disseminated cells should establish their growth in a new organ.

In addition to our study, which was based on use of a genetic mouse model for breast cancer, another recently published study provided strong evidence of a fibroblast-dependent niche for human breast cancer cells [52]. That study shows that human primary isolated CAFs, and normal fibroblasts exposed to tumor cell conditioned medium, express and release high levels of the chemokine CCL2 (monocyte chemotactic protein-1) which promoted the sphere forming capacity of different breast cancer cell lines. In contrast to findings in our experiments, the group also found a significant increase in the potential to form secondary spheres in non-conditioned control medium for cells derived from spheroids grown in the presence of CAF conditioned medium or CCL2, which indicates that the stem cell properties of these cells were no longer dependent on external factors.

It was found that the increase in secondary sphere formation was mainly due to CCL2 induced self-renewal of already existing CSCs rather than reprogramming of non-CSCs. CCL2 was found to activate Notch signaling as indicated by an upregulation of HES- 1 and Notch1 relative mRNA expression. These results were supported by IHC analysis of CCL 2 and Notch 1 on primary breast cancer species showing a correlation between upregulated CCL2 and Notch1 and a poor differentiation status of the tumor [52]. An important role for Notch activation in CSC self-renewal has been described for glioblastoma CSCs where endothelial cell-derived factors were identified as key components for CSC Notch activation [53].

Taken together, our own studies and other published work strongly suggest that CAFs play a central role in regulating CSC phenotypes by providing regulatory factors such as HGF, IL-6, chemokines, members of the TGF-beta family and factors activating Wnt signaling (table 1). Collectively, the studies imply targeting of CAFs or CAF-derived factors as a therapeutic option for attacking and erasing CSCs, and thereby also reducing the risk of metastasis outgrowth or tumor relapse.

Table 1. Fibroblast derived factors in normal and cancer stem cell niches. n.d.=not defined

\begin{tabular}{lcc}
\hline & \multicolumn{2}{c}{ Fibroblast derived factors } \\
\cline { 2 - 3 } Stem cell niche & normal & cancer \\
\hline intestine crypts & BMPs[15,25] & HGF[34] \\
mammary gland & n.d. & CCL2[52], IL-6[66] \\
pancreas & n.d. & Nodal, Activin[44] \\
\hline
\end{tabular}



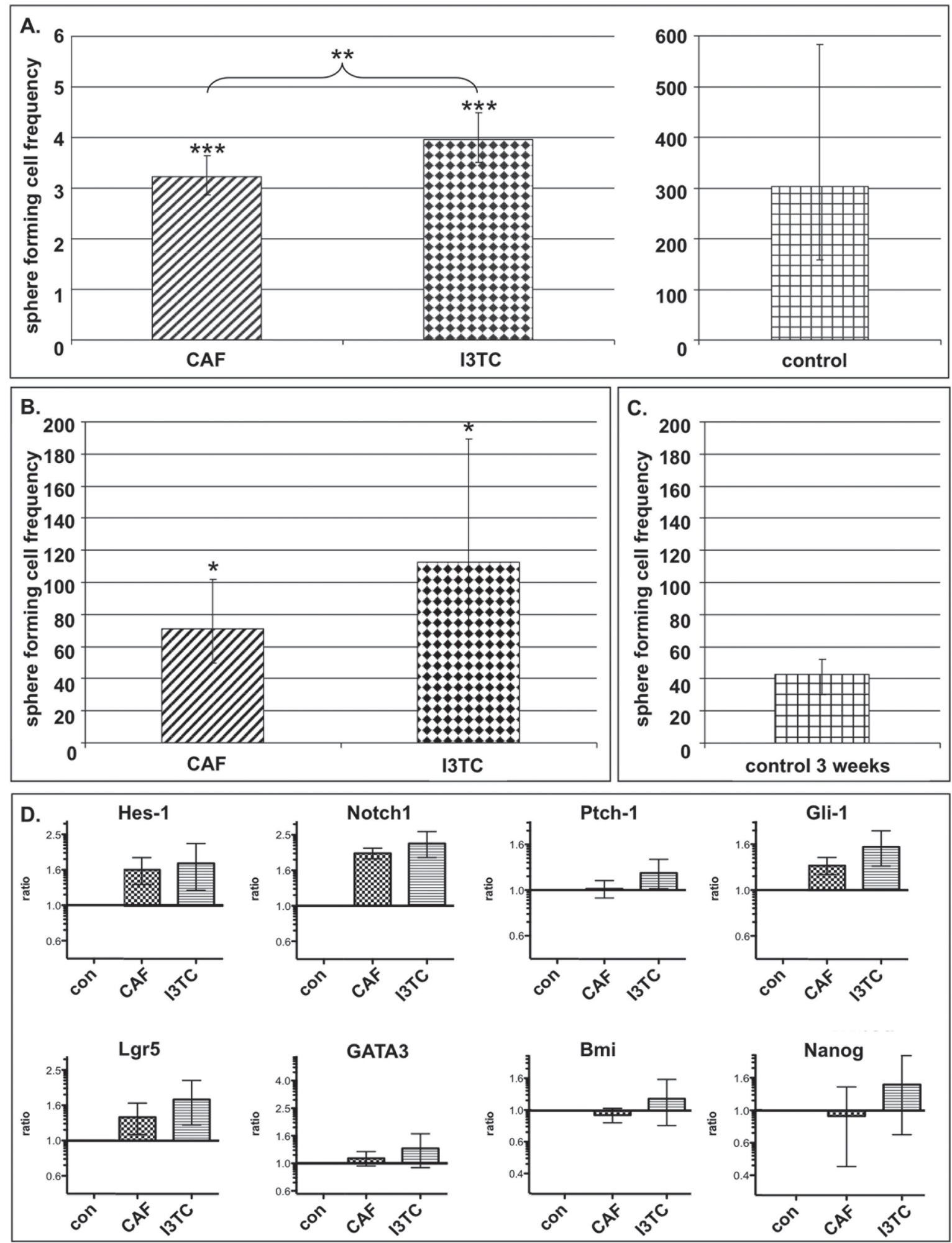

Figure 2. Analysis of sphere forming ability and gene expression of I3TC tumor cells after exposure to CAF conditioned medium (A) Results of 1st LDA with I3TC in non-conditioned medium (control), CAF conditioned medium and tumor cell (I3TC) conditioned medium. Spheroids were counted after 2 weeks. Tumor spheres were collected and used for a 2nd LDA in non-conditioned medium (B), which was analysed after 3 weeks. (C) According to the results of the 2nd LDA the control spheres of the 1st LDA were also counted after 3 weeks to enable comparison. Represented is the sphere forming cell frequency as $1 / \mathbf{n}$ cells; ${ }^{* * *}: p<0,0001 ;^{* *}: p<0,01 ;^{*}: p<0,05$. (D) CAF and tumor cell conditioned media had only a slight influence on the gene expression level of tumor spheres. The data is presented as the expression ratio $\left(\right.$ ratio $\left.=2^{-\Delta \Delta C T}\right)$ towards the spheroids grown in non-conditioned medium (control). 
Fibroblasts regulating CSCs in (pre-)metastatic niches. A large majority of cancer deaths are caused by metastatic disease $[54,55]$. Coghlin and Murray [56] define metastasis as 'the development of secondary tumors at a distance from primary site of cancer'. This multistage process includes the acquisition of a wide range of abilities such as the loss of cellular adhesion, increased invasiveness, intravasation and survival in the vascular system followed by extravasation and survival and proliferation in a new organ site [54]. Recent reviews have also revisited the seed-and-soil concept and emphasized the importance of a hospitable microenvironment to initiate growth of a secondary tumor [14,57].

Besides their involvement in CSC niches at the primary tumor site, fibroblasts are also described as contributing to the formation of the (pre-)metastatic niche. It is suggested that stromal niche signals play a crucial role in the initiation of metastatic growth. The group of Huelsken [58] was recently able to define one of these stromal signals. They identified periostin, a component of the extracellular matrix, as a key player in the metastatic colonization of breast tumors in the MMTV-PyMT genetic mouse model. This study showed that periostin is expressed by CAFs at the primary tumor site but also became induced in the stroma of secondary target organs by infiltrating cancer cells. The data gave strong evidence that the stromal production of periostin determines the metastatic efficiency. Based on tandem affinity purification-tag enrichment and tandem mass spectrometry periostin was found to bind to Wnt ligands in a way, which enhanced their CSC-stimulatory effects. The authors could further demonstrate that periostin deficiency has no effect on the primary tumor formation or the relative size of the CSC population at the primary tumor site, but specifically prevents the initiation of metastatic growth in the secondary site [58].

Other stromal derived components, which play a role in metastasis, were described in the work of O'Connell et al [59]. They used a transgenic mouse model to investigate the role of a particular subset of stromal cells in metastasis. These mice expressed a viral thymidine kinase under the control of a S100A4 promotor allowing specific ablation of S100A4 $4^{+}$ stromal cells. Orthotopic injection of 4T1 breast tumor cells led to an accumulation of S100 $4^{+}$cells at the primary tumor site and within the metastatic environment of the lungs. Depletion of these S100A4 $4^{+}$cells attenuated metastasis and increased apoptosis within metastatic foci. Additionally they could identify that the majority of the $\mathrm{S} 100 \mathrm{~A} 4^{+}$stromal cells, which affect metastasis, are fibroblasts. Subsequent studies implied Tenascin-C as a particularly important pro-metastatic $\mathrm{S} 100 \mathrm{~A} 4^{+}$cell-derived factor.

These findings are in agreement with other findings showing that Tenascin-C, in an autocrine way, enhances the expression of stem cell signaling factors like musashi homolog 1 (MSI1) and leucine-rich repeat-containing G-protein-couple-receptor 5 (LGR5) in breast cancer cells and thereby increases their capacity to form pulmonary metastases [60]. Tenascin-C has also been discussed as an important component of neural stem/progenitor cell niches [61].
The group of McAllister [62] has uncovered an additional mechanism whereby tumor-derived systemic signaling can promote the formation of a metastasis-permissive stroma at distant sites. This was demonstrated in a study of instigator-responder tumors, where it was shown that a subset of hematopoietic bone marrow cells became activated by tumor released endocrine factors and subsequently, through secretion of granulin, induced proinflammatory and matrix-remodeling genes in tissue fibroblasts.

Together these selected examples suggest that targeting the metastatic niche, or signals, which promote the formation of this niche could serve as a novel and promising strategy for adjuvant treatments.

Summary. Based on recent literature and our own experimental findings, this review emphasizes, that CAFs have a strong regulatory impact on the growth of CSCs or the induction of a stem cell like phenotype. However, it should be noted that this is not a CAF-specific feature, since tumor cells themselves and other cell types of the tumor microenvironment also release factors that induce and regulate stem cell pathways. All in all, recent data point towards a high complexity and redundancy of the CSC niche within the primary tumor that can compensate for the loss of a single factor. Eventually the CSC modulation of fibroblasts is most important in the case of disseminated CSCs. If this is indeed the case a set of most interesting and novel strategies for adjuvant cancer treatments can be envisioned.

\section{Materials and methods}

Cell isolation and culture. CAFs as well as the tumor cells were obtained from the MMTV PyMT mammary mouse tumor model [47] in FVB background.

Isolation of CAFs from the tumor tissue was adapted from a previously published outgrowth assay [63] with minor modifications. The tissue pieces were cultured in high glucose DMEM (ThermoScientific, Sweden) medium supplemented with $10 \%$ fetal bovine serum (ThermoScientific) and $5 \mu \mathrm{g} / \mathrm{ml}$ insulin (Sigma-Aldrich Sweden AB) The outgrown fibroblasts were collected by trypsinisation when confluent. The cells were immortalized by serial passaging as described in [64].

The tumor cells (I3TC) were isolated in a similar way. A tumor piece was mechanically homogenized, resuspended in DMEM media and filtered through a $100 \mu \mathrm{m}$ cell strainer. Contaminating fibroblasts were removed by brief trypsinisation.

PCR analysis was performed to exclude any epithelial/fibroblast, endothelial or immune cell contaminations.

Fibroblast/tumor cell conditioned medium was generated by incubation of the cells at $75 \%$ confluence for $24 \mathrm{~h}$ in DMEM:F12 w/o serum. Media was collected and centrifuged at $4000 \mathrm{rpm}$ for $10 \mathrm{~min}$ at $4^{\circ} \mathrm{C}$ to remove any cell debris.

Limited Dilution Assay - first round. A single cell suspension of tumor cells was generated by trypsin and disapase (StemCellTechnologies, Grenoble, France) treatment. The cells 
were seeded in a descending cell number $(16,8,4,2,1$ per well) in Ultra-Low Attachment (Corning) 96-well plates in fibroblast-, tumor cell- and non-conditioned medium, all diluted 1:2 with complete CSC medium (GlutaMax supplemented with $4 \mu \mathrm{g} / \mathrm{ml}$ heparin (StemCellTechnologies), B27 without vitamin A (LifeTechnologies), $5 \mu \mathrm{g} / \mathrm{ml}$ human insulin (Sigma-Aldrich), 20ng/ml EGF and 10ng/ml bFGF (both LifeTechnologies)). Fresh conditioned/non-conditioned medium was added every six days. After two weeks wells containing spheres larger than $50 \mu \mathrm{m}$ were counted.

Limited Dilution Assay - second round. Spheres were collected from the first LDA and separated using TrypLE ${ }^{\mathrm{T}}$ ${ }^{\mathrm{M}}$ Express (LifeTechnologies) and a $40 \mu \mathrm{m}$ cell strainer. Cells from the different conditions were seeded in descending cell numbers in non-conditioned medium. Fresh medium was added every 6 days.

RNA Preparation and quantitative real time PCR. RNA was isolated with GenElute ${ }^{\mathrm{TM}}$ Mammalian Total RNA Miniprep Kit (Sigma-Aldrich) according to manufacturer's instructions. cDNA synthesis was performed by using SuperScript ${ }^{\mathrm{TM}}$ III Reverse Transcriptase (LifeTechnologies) with random hexamer primers. Quantitative real time PCR was accomplished using Power SYBR Green PCR Master Mix (LifeTechnologies) in accordance with manufacturer's protocol. Primer sequences: Bmi (fwd: TCTTTTCCGCCCGCTCAGATCG; rev: ACCCTCCACACAGGACACACATTAA), Nanog (fwd: CTGATTCAGAAGGGCTCAGCACCAG; rev: GGTCCAGGTCTGGCTGCTCCAA),GATA3(fwd:AAGGCAACCACGTCCCGTCC, rev: CGGCATACCTGGCTCCCGTG), Hes-1 (fwd: CGGCCTCTGAGCACAGAAAGTCATC; rev: TCTAGCTTGGAATGCCGGGAGC), Notch-1 (fwd: TGCCACAATGAGATCGGCTC; rev: GGGCACATAGGGCAGTTCA),Lgr5(fwd:CGCCTTCCCCAGGTCCCTTCAA; rev: CCGTGGTCCACACCCCGATTC), Ptch1 (fwd: GTGCCTCAAGCGCACCGGA; rev: ACCACAGCAGCCTGGAGGGAG),Gli-1(fwd: GTGCACGTTTGAAGGCTGTCGG; rev: TGTGCGACCGAAGGTGCGTC) and GAPDH (fwd: ATTGTCAGCAATGCATCCTG; rev: ATGGACTGTGGTCATGAGCC).

Data and statistical analysis. LDA data were analysed with extreme limiting dilution analysis software (ELDA) [65] to estimate the frequency of sphere forming cells. The data is presented as the estimated frequency of sphere forming cells \pm upper/lower confidence interval.

The qPCR-results were analysed using the standard $\Delta \Delta \mathrm{C}_{\mathrm{T}}$ method. The expression level of GAPDH was used as endogenous reference for normalization $\left(\Delta \mathrm{C}_{\mathrm{T}}\right)$, and the expression is calibrated towards control spheroids $\left(\Delta \Delta \mathrm{C}_{\mathrm{T}}\right)$. The data is presented as the expression ratio ( $\mathrm{ratio}=2^{-\Delta \Delta \mathrm{CT}}$ ). GraphPad Prism 5 was used to calculate the statistical significance using One-way ANOVA with Bonferroni post hoc test.

Acknowledgements: C Strell was supported by the German Academic Exchange Service (DAAD) and the Breast Cancer Theme Center (BRECT), Karolinska Institutet.

\section{References}

[1] MAGEE JA, PISKOUNOVA E, MORRISON SJ Cancer stem cells: impact, heterogeneity, and uncertainty. Cancer Cell 2012; 21: 283-296. http://dx.doi.org/10.1016/j.ccr.2012.03.003

[2] AL-HAJJ M, WICHA MS, BENITO-HERNANDEZ A, MORRISON SJ, CLARKE MF Prospective identification of tumorigenic breast cancer cells. Proc Natl Acad Sci USA 2003; 100: 3983-3988. http://dx.doi.org/10.1073/pnas.0530291100

[3] LIU H, PATEL MR, PRESCHER JA, PATSIALOU A, QIAN D, et al. Cancer stem cells from human breast tumors are involved in spontaneous metastases in orthotopic mouse models. Proc Natl Acad Sci USA 2010; 107: 18115-18120. http://dx.doi. org/10.1073/pnas.1006732107

[4] LI X, LEWIS MT, HUANG J, GUTIERREZ C, OSBORNE $\mathrm{CK}$, et al. Intrinsic resistance of tumorigenic breast cancer cells to chemotherapy. J Natl Cancer Inst 2008; 100: 672-679. http://dx.doi.org/10.1093/jnci/djn123

[5] WICHA MS, LIU S, DONTU G Cancer stem cells: an old idea--a paradigm shift. Cancer Res 2006; 66: 1883-1890; discussion 1895-1896.

[6] COLLINS AT, BERRY PA, HYDE C, STOWER MJ, MAITLAND NJ Prospective Identification of Tumorigenic Prostate Cancer Stem Cells. Cancer Res 2005; 65: 10946-10951. http:// dx.doi.org/10.1158/0008-5472.CAN-05-2018

[7] RICCI-VITIANI L, LOMBARDI DG, PILOZZI E, BIFFONI $\mathrm{M}$, TODARO $\mathrm{M}$, et al. Identification and expansion of human colon-cancer-initiating cells. Nature 2007; 445: 111-115. http://dx.doi.org/10.1038/nature05384

[8] SINGH SK, CLARKE ID, TERASAKI M, BONN VE, HAWKINS C, et al. Identification of a cancer stem cell in human brain tumors. Cancer Res 2003; 63: 5821-5828.

[9] LI C, HEIDT DG, DALERBA P, BURANT CF, ZHANG L, et al. Identification of Pancreatic Cancer Stem Cells. Cancer Res 2007; 67: 1030-1037. http://dx.doi.org/10.1158/0008-5472. CAN-06-2030

[10] PIETRAS K, OSTMAN A Hallmarks of cancer: interactions with the tumor stroma. Exp Cell Res 2010; 316: 1324-1331. http://dx.doi.org/10.1016/j.yexcr.2010.02.045

[11] JONES DL, WAGERS AJ No place like home: anatomy and function of the stem cell niche. Nat Rev Mol Cell Biol 2008; 9: 11-21. http://dx.doi.org/10.1038/nrm2319

[12] FUCHS E, TUMBAR T, GUASCH G Socializing with the neighbors: stem cells and their niche. Cell 2004; 116: 769-778. http://dx.doi.org/10.1016/S0092-8674(04)00255-7

[13] KORKAYA H, LIU S, WICHA MS Breast cancer stem cells, cytokine networks, and the tumor microenvironment. J Clin Invest 2011; 121: 3804-3809. http://dx.doi.org/10.1172/JCI57099

[14] BOROVSKI T, DE SOUSA E MELO F, VERMEULEN L, MEDEMA JP Cancer stem cell niche: the place to be. Cancer Res 2011; 71: 634-639. http://dx.doi.org/10.1158/0008-5472. CAN-10-3220

[15] MEDEMA JP, VERMEULEN L Microenvironmental regulation of stem cells in intestinal homeostasis and cancer. Nature 2011; 474: 318-326. http://dx.doi.org/10.1038/nature10212

[16] LIAO C-P, ADISETIYO H, LIANG M, ROY-BURMAN P Cancer stem cells and microenvironment in prostate cancer 
progression. Horm Cancer 2010; 1: 297-305. http://dx.doi. org/10.1007/s12672-010-0051-5

[17] BRUNO RD, SMITH GH Reprogramming non-mammary and cancer cells in the developing mouse mammary gland. Seminars in Cell \& Developmental Biology 2012; http://dx.doi. org/10.1016/j.semcdb.2012.03.007

[18] SCHOFIELD R The relationship between the spleen colonyforming cell and the haemopoietic stem cell. Blood Cells 1978; 4: 7-25.

[19] FRIDRIKSDOTTIR AJR, PETERSEN OW, RØNNOV-JESSEN L Mammary gland stem cells: current status and future challenges. Int J Dev Biol 2011; 55: 719-729. http://dx.doi. org/10.1387/ijdb.113373af

[20] FUCHS E The tortoise and the hair: slow-cycling cells in the stem cell race. Cell 2009; 137: 811-819. http://dx.doi. org/10.1016/j.cell.2009.05.002

[21] FUCHS E, NOWAK JA Building epithelial tissues from skin stem cells. Cold Spring Harb Symp Quant Biol 2008; 73: 333-350. http://dx.doi.org/10.1101/sqb.2008.73.032

[22] EHNINGER A, TRUMPP A The bone marrow stem cell niche grows up: mesenchymal stem cells and macrophages move in. J Exp Med 2011; 208: 421-428. http://dx.doi.org/10.1084/ jem.20110132

[23] OH I-H, KWON K-R Concise review: multiple niches for hematopoietic stem cell regulations. Stem Cells 2010; 28: 1243-1249.

[24] AUCLAIR BA, BENOIT YD, RIVARD N, MISHINA Y, PERREAULT N Bone morphogenetic protein signaling is essential for terminal differentiation of the intestinal secretory cell lineage. Gastroenterology 2007; 133: 887-896. http://dx.doi. org/10.1053/j.gastro.2007.06.066

[25] HE XC, ZHANG J, TONG W-G, TAWFIK O, ROSS J, et al. BMP signaling inhibits intestinal stem cell self-renewal through suppression of Wnt-beta-catenin signaling. Nat Genet 2004; 36: 1117-1121. http://dx.doi.org/10.1038/ng1430

[26] RONNOV-JESSEN L, PETERSEN OW, BISSELL MJ Cellular changes involved in conversion of normal to malignant breast: importance of the stromal reaction. Physiol Rev 1996; 76: 69-125.

[27] KUPERWASSER C, CHAVARRIA T, WU M, MAGRANE G, GRAY JW, et al. Reconstruction of functionally normal and malignant human breast tissues in mice. Proc Natl Acad Sci USA 2004; 101: 4966-4971. http://dx.doi.org/10.1073/ pnas.0401064101

[28] PARMAR H, YOUNG P, EMERMAN JT, NEVE RM, DAIRKEE S, et al. A novel method for growing human breast epithelium in vivo using mouse and human mammary fibroblasts. Endocrinology 2002; 143: 4886-4896. http://dx.doi. org/10.1210/en.2002-220570

[29] EIREW P, STINGL J, RAOUF A, TURASHVILI G, APARICIO $S$, et al. A method for quantifying normal human mammary epithelial stem cells with in vivo regenerative ability. Nat Med 2008; 14: 1384-1389. http://dx.doi.org/10.1038/nm.1791

[30] BAI L, ROHRSCHNEIDER LR s-SHIP promoter expression marks activated stem cells in developing mouse mammary tissue. Genes Dev 2010; 24: 1882-1892. http://dx.doi. org/10.1101/gad.1932810
[31] OSTMAN A, AUGSTEN M Cancer-associated fibroblasts and tumor growth-bystanders turning into key players. Curr Opin Genet Dev 2009; 19: 67-73. http://dx.doi.org/10.1016/ j.gde.2009.01.003

[32] KALLURI R, ZEISBERG M Fibroblasts in cancer. Nat Rev Cancer 2006; 6: 392-401. http://dx.doi.org/10.1038/nrc1877

[33] ORIMO A, WEINBERG RA Stromal fibroblasts in cancer: a novel tumor-promoting cell type. Cell Cycle 2006; 5: 1597-1601. http://dx.doi.org/10.4161/cc.5.15.3112

[34] VERMEULEN L, DE SOUSA E MELO F, VAN DER HEIJDEN M, CAMERON K, DE JONG JH, et al. Wnt activity defines colon cancer stem cells and is regulated by the microenvironment. Nat Cell Biol 2010; 12: 468-476. http://dx.doi. org/10.1038/ncb2048

[35] AUGSTEN M, HAGGlof C, Olsson E, STOLZ C, TSAGOZIS P, et al. CXCL14 is an autocrine growth factor for fibroblasts and acts as a multi-modal stimulator of prostate tumor growth. Proc Natl Acad Sci USA 2009; 106: 3414-3419. http://dx.doi.org/10.1073/pnas.0813144106

[36] ORIMO A, GUPTA PB, SGROI DC, ARENZANA-SEISDEDOS F, DELAUNAY T, et al. Stromal fibroblasts present in invasive human breast carcinomas promote tumor growth and angiogenesis through elevated SDF-1/CXCL12 secretion. Cell 2005; 121:335-348. http://dx.doi.org/10.1016/ j.cell.2005.02.034

[37] TANIWAKI K, FUKAMACHI H, KOMORI K, OHTAKE Y, NONAKA T, et al. Stroma-derived matrix metalloproteinase (MMP)-2 promotes membrane type 1-MMP-dependent tumor growth in mice. Cancer Res 2007; 67: 4311-4319. http://dx.doi.org/10.1158/0008-5472.CAN-06-4761

[38] LIU S, GINESTIER C, OU SJ, CLOUTHIER SG, PATEL SH, et al. Breast cancer stem cells are regulated by mesenchymal stem cells through cytokine networks. Cancer Res 2011; 71: 614-624. http://dx.doi.org/10.1158/0008-5472.CAN-10$\underline{0538}$

[39] D’ANGELO RC, WICHA MS Stem cells in normal development and cancer. Prog Mol Biol Transl Sci 2010; 95: 113-158. http://dx.doi.org/10.1016/B978-0-12-385071-3.00006-X

[40] BRABLETZ T, JUNG A, REU S, PORZNER M, HLUBEK F, et al. Variable beta-catenin expression in colorectal cancers indicates tumor progression driven by the tumor environment. Proc Natl Acad Sci USA 2001; 98: 10356-10361. http://dx.doi. org/10.1073/pnas.171610498

[41] DONNENBERG VS, DONNENBERG AD, ZIMMERLIN L, LANDRENEAU RJ, BHARGAVA R, et al. Localization of CD44 and CD90 positive cells to the invasive front of breast tumors. Cytometry B Clin Cytom 2010; 78: 287-301.

[42] CHAFFER CL, BRUECKMANN I, SCHEEL C, KAESTLI AJ, WIGGINS PA, et al. Normal and neoplastic nonstem cells can spontaneously convert to a stem-like state. Proc Natl Acad Sci USA 2011; 108: 7950-7955. http://dx.doi.org/10.1073/ pnas. 1102454108

[43] SCHEEL C, EATON EN, LI SH-J, CHAFFER CL, REINHARDT F, et al. Paracrine and autocrine signals induce and maintain mesenchymal and stem cell states in the breast. Cell 2011; 145: 926-940. http://dx.doi.org/10.1016/ j.cell.2011.04.029 
[44] LONARDO E, HERMANN PC, MUELLER M-T, HUBER S, BALIC A, et al. Nodal/Activin signaling drives self-renewal and tumorigenicity of pancreatic cancer stem cells and provides a target for combined drug therapy. Cell Stem Cell 2011; 9: 433-446. http://dx.doi.org/10.1016/j.stem.2011.10.001

[45] NEESSE A, MICHL P, FRESE KK, FEIG C, COOK N, et al. Stromal biology and therapy in pancreatic cancer. Gut 2011; 60: 861-868. http://dx.doi.org/10.1136/gut.2010.226092

[46] SHIMIZU K Mechanisms of pancreatic fibrosis and applications to the treatment of chronic pancreatitis. J Gastroenterol 2008; 43: 823-832. http://dx.doi.org/10.1007/s00535-0082249-7

[47] LIN EY, JONES JG, LI P, ZHU L, WHITNEY KD, et al. Progression to malignancy in the polyoma middle $\mathrm{T}$ oncoprotein mouse breast cancer model provides a reliable model for human diseases. Am J Pathol 2003; 163: 2113-2126. http://dx.doi. org/10.1016/S0002-9440(10)63568-7

[48] LIU S, DONTU G, MANTLE ID, PATEL S, AHN N, et al. Hedgehog signaling and Bmi-1 regulate self-renewal of normal and malignant human mammary stem cells. Cancer Res 2006; 66: 6063-6071. http://dx.doi.org/10.1158/0008-5472. CAN-06-0054

[49] LEIS O, EGUIARA A, LOPEZ-ARRIBILLAGA E, ALBERDI MJ, HERNANDEZ-GARCIA S, et al. Sox2 expression in breast tumours and activation in breast cancer stem cells. Oncogene 2012; 31: 1354-1365. http://dx.doi.org/10.1038/ onc.2011.338

[50] LAGADEC C, VLASHI E, DELLA DONNA L, DEKMEZIAN C, PAJONK F Radiation-induced reprogramming of breast cancer cells. Stem Cells 2012; 30: 833-844. http://dx.doi. org/10.1002/stem.1058

[51] XIAO Y, YE Y, YEARSLEY K, JONES S, BARSKY SH The lymphovascular embolus of inflammatory breast cancer expresses a stem cell-like phenotype. Am J Pathol 2008; 173: 561-574. http://dx.doi.org/10.2353/ajpath.2008.071214

[52] TSUYADA A, CHOW A, WU J, SOMLO G, CHU P, et al. CCL2 mediates crosstalk between cancer cells and stromal fibroblasts that regulates breast cancer stem cells. Cancer Research 2012; http://dx.doi.org/10.1158/0008-5472.CAN11-3567

[53] ZHU TS, COSTELlO MA, TALSMA CE, FLACK CG, CROWLEY JG, et al. Endothelial cells create a stem cell niche in glioblastoma by providing $\mathrm{NOTCH}$ ligands that nurture self-renewal of cancer stem-like cells. Cancer Res 2011; 71: 6061-6072. http://dx.doi.org/10.1158/0008-5472.CAN-10$\underline{4269}$

[54] CHAFFER CL, WEINBERG RA A perspective on cancer cell metastasis. Science 2011; 331: 1559-1564. http://dx.doi. org/10.1126/science. 1203543
[55] SETHI N, KANG Y Unravelling the complexity of metastasis - molecular understanding and targeted therapies. Nat Rev Cancer 2011; 11: 735-748. http://dx.doi.org/10.1038/ $\underline{\operatorname{nrc} 3125}$

[56] COGHLIN C, MURRAY GI Current and emerging concepts in tumour metastasis. J Pathol 2010; 222: 1-15. http://dx.doi. org/10.1002/path.2727

[57] KAPLAN RN, RAFII S, LYDEN D Preparing the "soil": the premetastatic niche. Cancer Res 2006; 66: 11089-11093. http://dx.doi.org/10.1158/0008-5472.CAN-06-2407

[58] MALANCHI I, SANTAMARIA-MARTINEZ A, SUSANTOE, PENG H, LEHR H-A, et al. Interactions between cancer stem cells and their niche govern metastatic colonization. Nature 2012; 481: 85-89. http://dx.doi.org/10.1038/nature10694

[59] O'CONNELL JT, SUGIMOTO H, COOKE VG, MACDONALD BA, MEHTA AI, et al. VEGF-A and Tenascin-C produced by S100A4+ stromal cells are important for metastatic colonization. Proc Natl Acad Sci USA 2011; 108: 16002-16007. http://dx.doi.org/10.1073/pnas.1109493108

[60] OSKARSSON T, ACHARYYA S, ZHANG XH-F, VANHARANTA S, TAVAZOIE SF, et al. Breast cancer cells produce tenascin $\mathrm{C}$ as a metastatic niche component to colonize the lungs. Nat Med 2011; 17: 867-874. http://dx.doi.org/10.1038/ nm.2379

[61] VON HOLST A Tenascin C in stem cell niches: redundant, permissive or instructive? Cells Tissues Organs (Print) 2008; 188: 170-177. http://dx.doi.org/10.1159/000112848

[62] ELKABETS M, GIFFORD AM, SCHEEL C, NILSSON B, REINHARDT F, et al. Human tumors instigate granulinexpressing hematopoietic cells that promote malignancy by activating stromal fibroblasts in mice. J Clin Invest 2011; 121: 784-799. http://dx.doi.org/10.1172/JCI43757

[63] TUXHORN JA, MCALHANY SJ, DANG TD, AYALA GE, ROWLEY DR Stromal cells promote angiogenesis and growth of human prostate tumors in a differential reactive stroma (DRS) xenograft model. Cancer Res 2002; 62: 3298-3307.

[64] TODARO GJ, GREEN H Quantitative studies of the growth of mouse embryo cells in culture and their development into established lines. J Cell Biol 1963; 17: 299-313. http://dx.doi. org/10.1083/jcb.17.2.299

[65] HU Y, SMYTH GK ELDA: extreme limiting dilution analysis for comparing depleted and enriched populations in stem cell and other assays. J Immunol Methods 2009; 347: 70-78. http://dx.doi.org/10.1016/j.jim.2009.06.008

[66] RUDNICK JA, ARENDT LM, KLEBBA I, HINDS JW, IYER V, et al. Functional heterogeneity of breast fibroblasts is defined by a prostaglandin secretory phenotype that promotes expansion of cancer-stem like cells. PLoS ONE 2011; 6: e24605. http://dx.doi.org/10.1371/journal.pone.0024605 